Discussion Papers
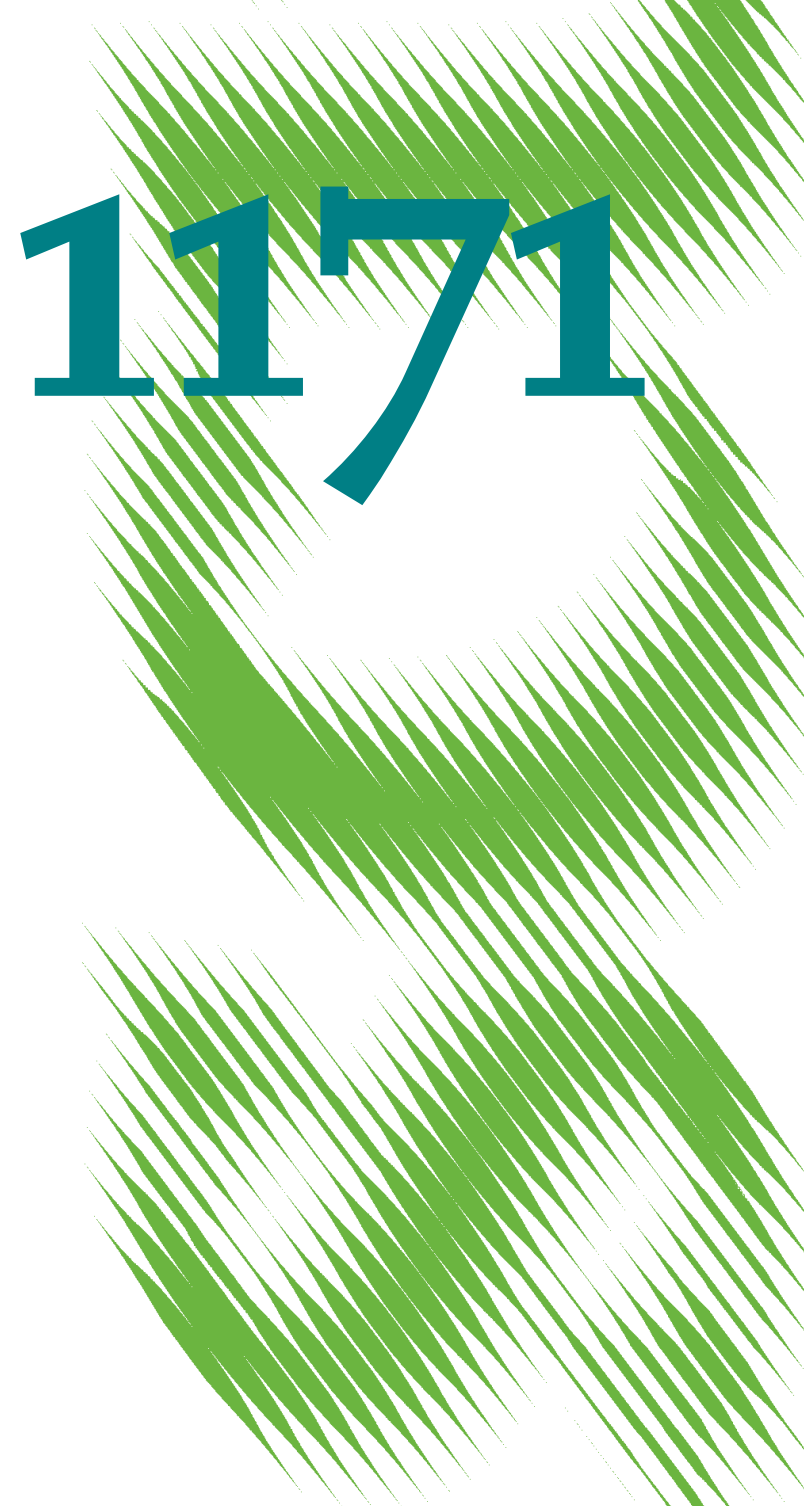

Transmission Investment in the Peruvian Electricity Market

Theory and Applications 
Opinions expressed in this paper are those of the author(s) and do not necessarily reflect views of the institute.

IMPRESSUM

(C) DIW Berlin, 2011

DIW Berlin

German Institute for Economic Research

Mohrenstr. 58

10117 Berlin

Tel. +49 (30) $89789-0$

Fax +49 (30) $89789-200$

http://www.diw.de

ISSN print edition 1433-0210

ISSN electronic edition 1619-4535

Papers can be downloaded free of charge from the DIW Berlin website:

http://www.diw.de/discussionpapers

Discussion Papers of DIW Berlin are indexed in RePEc and SSRN:

http://ideas.repec.org/s/diw/diwwpp.html

http://www.ssrn.com/link/DIW-Berlin-German-Inst-Econ-Res.html 


\title{
Transmission Investment in the Peruvian Electricity Market: Theory and Applications
}

\author{
Erix Ruiz \\ and \\ Juan Rosellón ${ }^{1}$
}

\begin{abstract}
$\underline{\text { Abstract }}$
This research presents an application of the Hogan, Rosellón and Vogelsang (2010) (HRV) mechanism to promote electricity transmission network expansion in the Peruvian electricity transmission system known as SEIN (Sistema Eléctrico Interconectado Nacional). The HRV mechanism combines the merchant and regulatory approaches to promote investment into transmission grids. This mechanism gives incentives for efficient investment in expansion of the network by the rebalancing over time of the fixed and variable charges of a two-part tariff in the framework of a wholesale electricity market with locational pricing. The expansion of the network is carried out through the sale of Financial Transmission Rights (FTR's) for the congested lines. The mechanism is applied for 103 nodes of the SEIN using detailed characteristics of generators, nodes and transmission lines. Under Laspeyres weights and linear cost of expansion of transmission capacity, it is shown that prices converge to lower levels as a result of increased transmission capacity.
\end{abstract}

Keywords: Electricity transmission expansion, incentive regulation, Peru, congestion management

JEL-codes: L51, L91, L94, Q40

${ }^{1}$ Corresponding autor: Centro de Investigación y Docencia Económicas (CIDE) and German Institute for Economic Research (DIW Berlin). Contact details: Mexico: División de Economía, Carretera México-Toluca 3655, Mexico, D.F., 01210, Mexico; Tel.: +52-55-57-27-9800, ext. 2711, fax: +52-55-57-27-9878; email: juan.rosellon@cide.edu; Germany: German Institute for Economic Research (DIW Berlin), Mohrenstrasse 58, 10117 Berlin, Germany, email: jrosellon@diw.de This author acknowledges support of the Programa Interinstitucional de Estudios sobre la Región de América del Norte (PIERAN) at El Colegio de México, the Alexander von Humboldt Foundation and Conacyt (p. 60334). 



\section{Introduction}

The electricity market reforms carried out in several countries since the 1990's were aimed at introducing competition in segments of the industry (organized historically as a natural monopoly) as the generation and distribution. Because of its characteristics, transmission segment has remained as a natural monopoly. Thus, due to problems related to coordination and capacity of transmission networks, electricity transmission grid expansion and pricing transmission have received increasing attention in recent years. ${ }^{1}$

It was then understood that without efficient transmission expansion, the electric grid in the near future would be stretched far beyond its capacity increasing substantially the final price of electric energy, affecting the economy. In this sense, the present work applies a mechanism that provides adequate incentives to expansion in electricity transmission networks in the Peruvian electricity transmission system. Following a recent application by Rosellón, Myslíkova and Zenon (2011), the work introduces some improvements, which are related with higher disaggregation of nodes and a more detailed model for the electricity dispatch.

The document is organized as follows. Section II presents the "state of the art" related with the literature on incentive mechanisms for the expansion of electricity transmission networks. Section III provides a description of the mechanism applied. It is a mechanism that combines the merchant and regulatory mechanisms in a problem that has two levels of a Transmission Company (Transco), and an Independent System Operator

\footnotetext{
${ }^{1}$ During 2003, problems related to coordination and capacity of transmission network partly caused power outages in the northeast of the US, which affected more than 20 million consumers. Similar events in other parts of the world such as UK, Italy, Sweden, Brazil, Argentina, Chile, New Zealand, and Germany, also awakened the interest in the factor that ensure reliability of transmission grids.
} 
(ISO). The Transco maximizes its flow of profits subject to a regulatory constraint (upper level problem). The ISO solves a problem of optimal dispatch with the objective of minimize the total cost of generation (lower level problem). The two levels are solved simultaneously. Section IV presents a revision of the features of the Peruvian electricity transmission system. Section V presents the information used in the simulations and the main results. Section VI concludes.

\section{The Literature}

The formal analysis of appropriate incentives for network expansion is complicated due to externalities generated by the physical characteristics of electricity itself as well as due to cost sub-additivity and economies of scale features of the grid. Externalities in electricity transmission are mainly due to 'loop flows', ${ }^{2}$ which arise from interactions in the transmission network. The effects of loop flows imply that transmission opportunity costs and pricing depend on the marginal cost of power at every location. Energy and transmission costs are not independent since they are determined simultaneously in the electricity dispatch and the spot market. Thus, certain transmission investments in a particular link might have negative externalities on the capacity of other transmission links.

The analysis of incentives for transmission investment is further complicated since the equilibria in the forward electricity transmission markets have to be coordinated with equilibria in other markets such as the energy spot market, the forward energy market, and the generation capacity-reserves market (Wilson, 2002). Likewise, electricity pricing is complicated since electricity is not storable, and because it has to simultaneously guide long-term investment decisions by transmission companies as well as to ration demands in the short run due to congestion. Furthermore, the effects of an increase in transmission

${ }^{2}$ Loop flow is the characteristic of electricity that takes it through all available routes (path of least resistance) to get from one point to another. 
capacity are uncertain. For instance, the net welfare outcome of an expansion in the transmission grid depends on the weight in the welfare preferences of the generators' profits relative to the consumers’ weight (Léautier, 2001).

The institutional structure of the system operator, and its relationship with the transmission network, are also key factors that define the alternatives that might attract new investment to the grid. There are three possible structures for a system operator (Wilson, 2002). The first is an independent system operator (ISO), different from the company that owns the transmission grid, which is decentralized and intrudes to the least possible extent in the markets. The second is a centralized ISO that controls and coordinate the markets. The third is an integrated company, the transmission company (Transco), which combines ownership of the transmission network with system operation.

The economic analysis of electricity market has usually concentrated on short-run issues as short-run congestion management, and nodal pricing. However, investment in transmission capacity is long run as well as stochastic. In the short run, the difference of electricity prices between nodes in a power-flow model defines the price of congestion (Hogan, 2002). Nevertheless, an 'optimal' way to attract investment for the long-run expansion of the transmission network is still an open question both formally, and in practice (Vogelsang, 2006).

This chapter presents a review of three analytical approaches to transmission investment: the first is based on the incentive-regulation hypothesis (performance-basedregulation (PBR) approach), the second employs the theory based on long-term financial 
transmission rights (LTFTRs) (merchant approach), while the third combines both mechanisms (merchant-regulatory approach). ${ }^{3}$

\subsection{The PBR Approach}

he PBR approach to transmission expansion depends on incentive-compatible regulatory mechanisms for a Transco. Such mechanisms provide the firm with incentives to make efficient investment decisions as well as earn enough revenues to recover capital and operating costs. The formal analyses of PBR mechanisms for transmission expansion basically rely on comparing a Transco's performance with a measure of welfare. The Transco is penalized for increasing congestion costs in the network, and is responsible for the costs of congestion it creates and the needed investment to relieve it.

Joskow and Tirole (2002) suggest a simple surplus-based model to provide the Transco with incentives to expand the transmission network. The idea is to reward the Transco according to the redispatch cost avoided by the expansion, so the Transco faces the entire social cost of congestion. This mechanism would presumably mitigate the problems associated with lumpiness and loop flows, but it could be subject to manipulation of bids in the energy market by a Transco vertically integrated with generation. With no vertical integration, generators might invest just what is needed to match existing transmission capacity.

In an alternative PBR approach, Vogelsang (2001) uses a price-cap structure regulation to solve transmission congestion, in the short run, as well as capital cost and investment issues in the long run. In a two-part tariff regulatory model with a variable

3 There is another alternative method for transmission expansion. This mechanism derives optimal transmission expansion from the power-market structure of electricity generation, and considers conjectures made bay each generator on other generators' marginal costs due to expansion (Wolak, 2000). Thus, it models the interdependence of generation and transmission investment. However, it also is based on a transportation model with no network loop flows. 
charge, and a fixed charge, the variable charge is mainly based on nodal prices and relieves congestion. Recuperation of long-term capital costs is achieved through the fixed charge that can be interpreted as the price for the right to use the transmission network. The incentives for efficient investment in expansion of the network in the Vogelsang model are reached by the rebalancing over time of the fixed and variable charges. Likewise, incentives for the investment depend on the type of weights used. For instance, a Laspeyres index uses the quantity of the previous period as weight for the price so that the Transco, under certain conditions, will intertemporally invest until its transmission tariffs converge to Ramsey prices. Thus, when there is congestion in capacity the Transco will expand the network because its profits increase with network expansion when congestion variable charges are marginally larger than the marginal cost of expanding capacity. On the contrary, in times of excess capacity, the variable charge of the two-part tariff will be reduced, increasing the consumption. The fixed charge, in turn, increases so that total income augments despite the decrease in the variable charge. As a consequence, the Transco ceases to invest in capacity expansion, and net profits expand since costs do not increase.

The price-cap approach in Vogelsang (2001), however, depends on simplifying assumptions that are not usually met in practice. Transmission demand functions are assumed differentiable and downward sloping, while transmission marginal costs curves are supposed to cut demand only once. ${ }^{4}$ Likewise, transmission activity is considered as a physical output (or throughput) process as opposed to a transmission output defined in terms of point-to-point transactions. Thus, under the definition of transmission output used

\footnotetext{
${ }^{4}$ These assumptions are generally invalid since, under loop flows, an expansion in a certain transmission link can result in decreases of other networks link leading to discontinuities in the marginal-cost function (Hogan, 2002).
} 
by Vogelsang (2001), the mechanism cannot be applied to meshed transmission network, only to radial lines.

Another problem of PBR mechanisms is their inconsistency with timing issues of transmission networks. Vogelsang (2006) proposes a framework based on the distinction on ultra-short period, short periods and long periods. The ultra-short period is motivated by real-time pricing of point-to-point transmission services, and there are no possibilities within this period for cost reductions. The short period coincides with the application of RPI-X factors, and is also the period for the calculation of the fixed fees. The long period is given by the regulatory lag of the PBR mechanism; that is, the time between (cost-ofservice) tariff revisions.

In the Vogelsang (2001) mechanism, investment in the grid occurs at the beginning of each period while fixed fees are calculated at the end of the period. Therefore, this mechanism implicitly lumps together the short and the long periods. The Vogelsang (2006) mechanism on the contrary combines the ultra-short, short and long periods and allows for the possibility of no investment for several short periods or even for times beyond a long period. This mechanism then depends on previous price performance of the mechanism in the past as well as on the long run certainty provided by revisions based on rate-of-return regulation.

\subsection{The Merchant Approach}

The merchant approach to transmission expansion is based on auctions of financial transmission rights (FTRs) that try to attract voluntary participation by potential investors ${ }^{5}$. Incremental FTRs provide market-based transmission pricing that attracts investment since it defines property rights.

\footnotetext{
${ }^{5}$ An FTR is a financial instrument that allows the value of increased transmission capacity to be security and auction competitive, allowing the entry of the private sector into transmission expansion (Hogan, 2002).
} 
FTR auctions are carried out within a bid-based security-constrained economic dispatch with nodal pricing of an ISO. The ISO runs a power-flow model that provides nodal prices derived from shadow prices of the model's constrains. FRTs are derived from the nodal prices differences according to transmission capacity between nodes. The projects of transmission expansion have a useful life of approximately 30 years, so the ISO allocates long-term FTRs (LTFTRs) through an auction so as to protect the holders from unexpected changes in congestion costs. Therefore, LTFTR auctions work in parallel with long-term generation contracts.

The formal analysis of FTR auctions can be divided into long-and short-term models. The short-run FTR models have remarkable results that provide efficiency only under a stringent set of assumptions related to perfect competition. ${ }^{6}$ An important aspect related to meshed networks with loop flows is that an addition in transmission capacity in a link of the network might result in a reduction of the capacity of other links. This, combined with asymmetry of information among the agents in the industry (generators, ISO, and transmission owners) might result in negative social value. In this sense, Kristiansen and Rosellón (2006) propose an alternative where the ISO retains some 'unallocated FTRs' in order to use in case those externalities arise during the expansion process.

The LTFTR models consider relevant all these insights. LTFTR auctions provide efficiency results under absence of market power and non-lumpy marginal expansions of the transmission network. Thus, regulation has an important role in large and lumpy

\footnotetext{
${ }^{6}$ These assumptions include: absence of market power and sunk costs, an ISO without an internal preference on effective transmission capacity, complete future markets, certainty over congestion rents, nodal price that internalize network externalities and that reflects the willingness to pay of consumers, as well as nonincreasing returns to scale (Joskow and Tirole, 2005)
} 
projects in order to mitigate market power and let LTFTR auctions provide efficient incentives to attract investment.

\subsection{The combined merchant- regulatory approach}

This approach combines the PBR and merchant transmission models so as to reconcile the dual short-run incentives to congest the grid, and the long-run incentives to invest in transmission expansion. The merchant mechanisms are best applied for incrementally small expansion in meshed networks under an ISO environment, while the price-cap mechanism regulates a monopoly Transco. Thus, large and lumpy project can be developed through PBR incentive regulation while the merchant approach can be used for small transmission expansion projects.

In this sense, Hogan et al. (2010) (HRV) combines the merchant and regulatory approach in a framework of price-taking generator and loads. The crucial aspects of the model are the redefinition of the transmission output in terms of incremental LTFTRs in order to apply the price-cap mechanism in Vogelsang (2001) and that the HRV model doesn't take any assumption about the behavior of cost and demand transmission functions. In the model, the Transco intertemporally maximizes profits subject to a cap on its two-part tariff scheme. ${ }^{7}$

In the HRV model there is a sequence of auctions at each period $t$ where participant buy and sell LTFTRs. The Transco maximizes expected profits at each auction subject to simultaneous feasibility constrain, and two-part tariff cap constrain while the transmission outputs are the incremental LTFTRs between consecutive periods.

\footnotetext{
${ }^{7}$ The fixed part of the tariff can be understood as a complementary charge that recover fixed cost, while the variable charge is the price of the FTR output, and is based on nodal prices.
} 
Rosellón and Weigt (2011) applies the HRV mechanism with an engineering approach in different network topologies. After an analysis of the behavior of cost functionin terms of FTRs-for distinct network topologies the HRV model is applied to Northwestern Europe. The results show that the HRV mechanism has the potential to attract investment in congested network. Similarly, Rosellón, Myslíková and Zenon (2011) show an application of the merchant-regulatory approach in the area of PJM system. The mechanism is tested for 14-zone and 17-zone geographical coverage areas of PJM. Using Laspeyres weights, it is shown that prices converge to the marginal cost of generation ${ }^{8}$, the congestion rent decreases and the total social welfare increases.

\section{The model}

The model applied integrates the concepts of incentive mechanisms described in the Section II, and is based on the modeling logic of Vogelsang (2001), HRV, and Rosellón and Weigt (2011). The model combines the merchant and regulatory mechanism with an engineering approach and merges the tools of two models for the adequate transmission expansion problem: a welfare optimization dispatch power-flow problem with a two-part tariff cap regulatory model (lower level and upper level problems respectively).

The model simulates the real transmission operation and planning issues faced by an ISO, and a Transco. It can model some crucial aspects of practical cases where (a) a central authority applies certain type of regulation, imposing a regulation constraint, (b) the Transco is subject to regulation constrain and charges a fee for the transmission service and plans the transmission expansion , and (c) the ISO, that operate the wholesale market, manages the electric dispatch subject to the characteristic and capacity limitation of the transmission network in order to dispatch electric power in an efficient way.

\footnotetext{
${ }^{8}$ The application shows that the prices adjust effectively given either non-peak or peak demand.
} 
The last three concepts are modeled in the following way:

1) The merchant mechanism is based on a system of nodal prices and FTRs. Transmission expansion is carried out through the sale of FTRs. FTRs are defined according to node pair that suffer congestion, and are commercialized via auctions where the participants enter voluntarily.

2) The regulatory part of the mechanism is based on Vogelsang (2001), a cap constraint is intertemporally applied over a two-part tariff.

3) The electric dispatch is modeled through a welfare costs minimization problem, subject to the engineering restrictions that reflects the technical limitation of the transmission network. It defines the wholesale prices in each short-run period.

A crucial aspect which allows the combination of the merchant and the regulatory mechanisms is the redefinition of the transmission output in terms of FTRs introduced by HRV. This approach solves the deficiency of Vogelsang (2001) with a convenient measure of transmission output as point-to-point transactions of FTR obligations. HRV shows that, under certain conditions, convergence to Ramsey prices can be reached.

The model is divides into two level- optimization (or two levels of optimization). The upper level problem represents a dynamic profit maximization problem solved by a Transco considering transmission expansion. It reflects the opposite incentives that the Transco faces (to expand the transmission network which releases congestion and produces long term benefits for the society, or keep congestion in the network and get high congestion rents). The lower level problem reflects the optimization problem faced by an ISO operating the wholesale market, which dispatches the generation and transmission optimally. So, the lower level problems define the wholesale market outcome. The two-part 
tariff maximization forms a dynamic optimization problem running thru $T$ periods, subject to complementary constraints. The two levels of the model are solved simultaneously.

\subsection{The Upper Level Problem}

The Transco maximizes the intertemporal flow of profit subject to a price cap constraint:

$$
\begin{gathered}
\operatorname{Max}_{k, F} \sum_{t}^{T}\left[\sum_{\substack{i=1 \\
j=1}}^{I} \tau_{i j}^{t}(k) q_{i j}^{t}(k)+F^{t} N^{t}-\sum_{\substack{i=1 \\
j=1}}^{I} c\left(k_{i j}^{t}\right)\right] \\
i \neq j
\end{gathered}
$$

Subject to:

$$
\frac{\sum_{i, j} \tau_{i j}^{t}(k) q_{i j}^{w}(k)+F^{t} N^{t}}{\sum_{i, j} \tau_{i j}^{-1}(k) q_{i j}^{w}(k)+F^{t-1} N^{t}} \leq 1+R P I-X
$$

Where the first basic source of revenue is the first term of the profit function. It represents the congestion rents. The congestion rent is generally defined as point-to-point FTRs, $q_{i j}^{t}(k)$, between two nodes $i$ and $j$, multiplied by the FTR price, $\tau_{i j}^{t}(k)$, which is set on the FTR auction. ${ }^{9}$ The second source of revenue is a fixed fee $F$ charged to each of $N$ users of the transmission grid. It represents a fixed payment for the access to the transmission network. The last term of the profit function represents the costs of transmission-line capacity expansion between the nodes $i$ and $j$ incurred by the Transco, $c\left(k_{i j}^{t}\right)$.

The constraint on revenue is the regulatory constraint imposed by the regulatory authority. The constraint is based on a two-part tariff cap. It allows rebalancing the parts of

\footnotetext{
${ }^{9}$ The congestion rent is only charged in the lines that generate "space" for new FTRs. If the limit of the overall capacity of a line is not reached during the transmission process in the period $t$, there are no FTRs generated on the line at $t$, and no congestion rents are reached by the Transco.
} 
the tariff and guarantees that the Transco will not lose income through the diminishing of the congestion rent when the transmission network is expanded. A lower congestion rent will in turn decrease profits. This is offset as the Transco counters the diminishing congestion rent by increasing the fixed fee.

The weights $w$ used in the price tariff are the Laspeyres weights. ${ }^{10}$ The price cap adjust for an efficiency factor, $X$, and an inflation factor, $R P I$. The Transco maximizes its profits subject to the regulatory constraint, through $T$ periods, considering the transmission lines between all the nodes $i$ and $j$ within the grid. Perfect information is assumed respect to the generation capacity, but is assumed that there is uncertainty about demand capacity.

In order to find the first-order optimality conditions, ignoring efficiency and the inflation factors, the derivative of the objective function (1) subject to the constrain (2) is:

$$
\nabla q_{i j}^{t} \tau_{i j}^{t}\left(k^{t}\right)-\nabla c^{*}=\left(q_{i j}^{w}-q_{i j}^{t}\left(k^{t}\right)\right) \nabla \tau_{i j}^{t}
$$

With the objective of simplify the application of this model. Rosellón and Weigt (2011) avoid the FTRs and redefine the system (1)-(2), so that the problem can be rewritten as:

$$
\begin{gathered}
\operatorname{Max}_{k, F} \sum_{t}^{T}\left[\sum_{i=1}^{I}\left(p_{i}^{t} d_{i}^{t}-p_{i}^{t} g_{i}^{t}\right)+F^{t} N^{t}-\sum_{\substack{i=1 \\
j=1}}^{I} c\left(k_{i j}^{t}\right)\right] \\
i \neq j
\end{gathered}
$$

Subject to:

$$
\frac{\sum_{i}\left(p_{i}^{t} d_{i}^{w}-p_{i}^{t} g_{i}^{w}\right)+F^{t} N^{t}}{\sum_{i}\left(p_{i}^{t-1} d_{i}^{w}-p_{i}^{t-1} g_{i}^{w}\right)+F^{t-1} N^{t}} \leq 1+R P I-X
$$

\footnotetext{
${ }^{10}$ According to Rosellón (2007), the Laspeyres weights applied to the Vogelsang (2001) two-part tariff mechanism allows a solution that converges to an optimum under stable cost and demand functions.
} 
The first term of (4) represents a redefinition of the congestion rent. This is defined now in terms of the market clearing prices, demand and generation at every node. It is defined as the difference between the payments from the loads, $p_{i}^{t} d_{i}^{t}$, and the payments to the generators, $p_{i}^{t} g_{i}^{t}$. If the loads pay the generators precisely the price that electricity costs at the place it was generate, then there are no congestion and congestion rent. ${ }^{11}$ The regulation constraint is written using the same logic.

\subsection{The Lower Level Problem}

This is a costs minimization problem, and determines the wholesale market outcome. The optimization of the electrical dispatch by the ISO is subject to the technical restrictions of the networks and power flows. It is assumed that the ISO minimize costs in a competitive environment.

$$
\operatorname{Min}\left\{\sum_{\substack{n=1 \\ t=1}}^{N, T} B C_{n}^{t}\left(g_{n}^{t}\right)\right\}
$$

Subject to:

$$
\begin{gathered}
g_{i}^{t} \leq g_{i}^{t, \max } \quad \forall i, t \quad \text { generation constraint at node } i \\
\left|p f_{i}^{t}\right| \leq k_{i, j}^{t} \quad \forall i, j \quad \text { line flow constraint between } i \text { and } j \\
g_{i}^{t}+q_{i}^{t}=d_{i}^{t} \quad \forall i, t \quad \text { energy balance constraint at node } i
\end{gathered}
$$

Where $B C_{n}^{t}$ is bid curve (\$/hr) with bid price and generation (normally quadratic) for unit $n$, which is described as:

\footnotetext{
${ }^{11}$ The relationship between the market clearing prices and the FTR prices is $\tau_{i j}=p_{j}-p_{i}$.
} 


$$
B C_{n}=a_{n} g_{n}^{2}+b_{n} g_{n}+c_{n}
$$

Where $a_{n}, b_{n} \mathrm{y} c_{n}$ are coefficients of the bid curve.

The first restriction, equation (7), is a capacity constraint that implies that any generation in any node $i$ cannot exceed its generation capacity. Equation (8) represents the restriction that the power flow $p f_{i}^{t}$ between the nodes $i$ and $j$ cannot exceed the transmission capacity $k_{i, j}^{t}$ of the line. The equation (9) imposes that demand at each node is satisfied by local generation or by a net injection $q_{i}^{t}$.

Then, solving the lower level problem, the vectors of optimal values of $d$ and $g$, as well as nodal prices $p$, are obtained and substituted into the upper level problem. Then the optimal values of capacity $k$ and fixed fee $F$ are in turn obtained.

\section{The Peruvian electricity transmission system}

The Peruvian electricity sector reform which started in 1992 with the enactment of the Ley de Concesiones Eléctricas (LCE) did not give sufficient incentives to make the necessary investment in transmission facilities, as was alleged in the regulatory framework. On the other hand, some factors related to the lack of incentives for contracts between generators and distributor, aggravated by a situation of a dry hydrological year 2004, originated the adoption of a second reform through the publication of the Ley para el Desarrollo Eficiente de la Generación Eléctrica in 2006. This new regulatory framework introduced a transmission market design similar to the standard market design (SMD) of USA proposed by the Federal Energy Regulatory Commission (FERC). This new market design is based on a nodal pricing system, a system of expansion planning of transmission and an auction system for coverage of energy demand. However, unlike the SMD market Peru did not enter the figure of Financial Transmission Rights (FTR), that because the analysis carried 
out at the time noted that the FTR's are not absolutely necessary in a nodal pricing system and further analysis was needed to determine whether it benefits outweigh its costs.

Parallel to this, the high rate of demand growth of around $10 \%$ in the last two years has caused that the transmission lines are operating near the limit of capacity and, with contingencies in the system, these facilities are congested with the consequent distortion in short term nodal energy prices. This volatility in price introduces risk in energy contract between generators and distributors, which in the end can evolve into a lack of contracts for the supply of energy to the regulated market.

The main problems related to the electricity transmission after the first reform were: The existence of an inefficient system for the transmission expansion that does not answer market requirements, the uncertainty caused by the use of the concept of Economic System Adapted (SEA) during the life of facility ${ }^{12}$, and an expansion of transmission networks which depends on market demand without a planning system to define the needs of expansion.

In the absence of investment by private actors, the principal investments in transmission have been executed by decision of the State or have been developed through mechanisms that are not covered by LCE. ${ }^{13}$ Other significant event is the concession of the transmission facilities of state companies with the largest transmission assets of the SEIN ${ }^{14}$ : ETECEN and ETESUR, it was held in September 2002. These assets were given in

\footnotetext{
12 This means that revenue earmarked for these facilities will change in relation to the requirement of transmission, regardless of actual investments.

13 Between 2000 and 2002, investments were conducted outside the regulatory framework through mechanisms of market competition, through the Agencia para la Promoción de la Inversión Privada (PROINVERSIÓN) by means of BOOT (Build, Operate, Own and Transfer) contracts. In this context, were built the interconnection of the electric systems Centre-North and South by the Company Transmantaro; booster lines were built in the South by the Company Red Eléctrica del Sur (REDESUR) and were built the lines La Oroya Nueva-Carhuamayo-Paragsha-Derivación Antamina y Aguaytía-Pucallpa, by the company Interconexión Eléctrica ISA Perú.

${ }^{14}$ SEIN (Sistema Eléctrico Interconectado Nacional).
} 
concession to REP (Red de Energía del Perú S.A.). Figure 1 shows the evolution of the investments in the electricity sector for the period 1994-2008. Transmission investments are no significant regarding the investments in generation and distribution.

Figure 1: Investments in the electricity sector (million US\$)

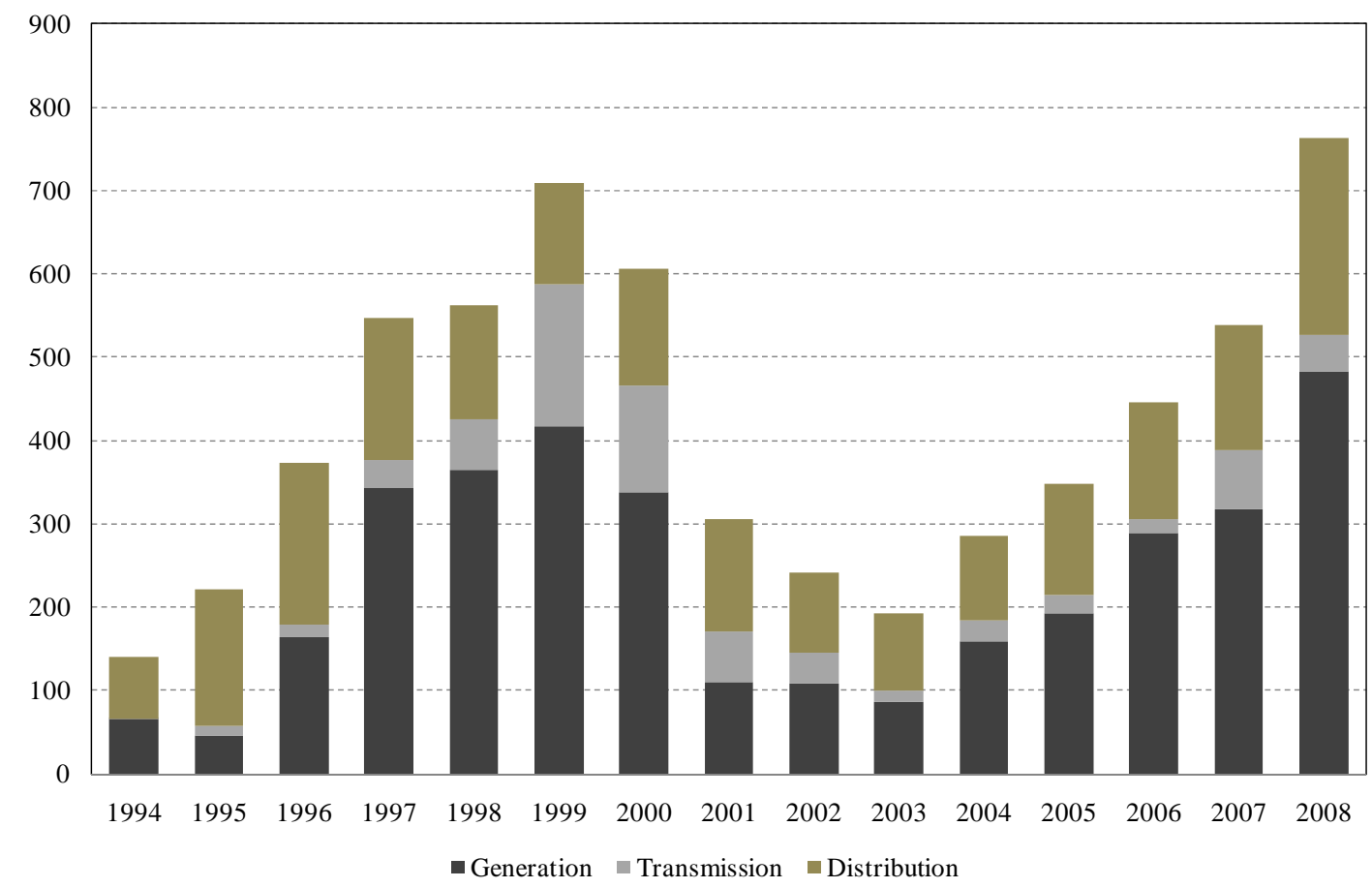

Source: MINEM

In relation to the second reform, this introduces substantial changes, among which the development of transmission by a centrally planned to be developed by the COES ${ }^{15}$ and approved by the Ministry of Energy and Mines and the OSINERGMIN ${ }^{16}$. Likewise, it is proposed the bidding to award concessions for the construction of new facilities contained in the transmission plan, whose compensation shall be done based on the value resulting from the tender, thus leaving aside the problems related to the concept of Economic System

\footnotetext{
${ }^{15}$ COES (Comité de Operación Económica del Sistema).

${ }^{16}$ OSINERGMIN (Organismo Supervisor de la Inversión en Energía y Minería).
} 
Adapted (SEA). In short, the pillars of this new market design focus to eliminate the uncertainty of recovery of investment in transmission facilities so that the transmission expansion is developed in a timely and efficient facilities, thereby effect to avoid structural bottlenecks.

Finally, Figure 2 shows the Peruvian electricity transmission system and the participation of generators in the electric market of SEIN. It can be seen that the Central zone of SEIN has the highest concentration of generation (73\%). This is because this area of the country has greater demand, mainly in Lima and in the mines located in the central highlands. In second place, is the Centre-North zone which concentrates $10 \%$ of national generation, then South West and South East with 7\% and 6\% respectively, and finally the North zone with just 3\% of national generation. This composition of the generation park is important because it influences the determination of the income of congestion. As will be seen on the results, the sense of congestion occurs from the center to north and south limits of the SEIN. 
Figure 2: Peruvian electricity transmission system and generation (GWh)

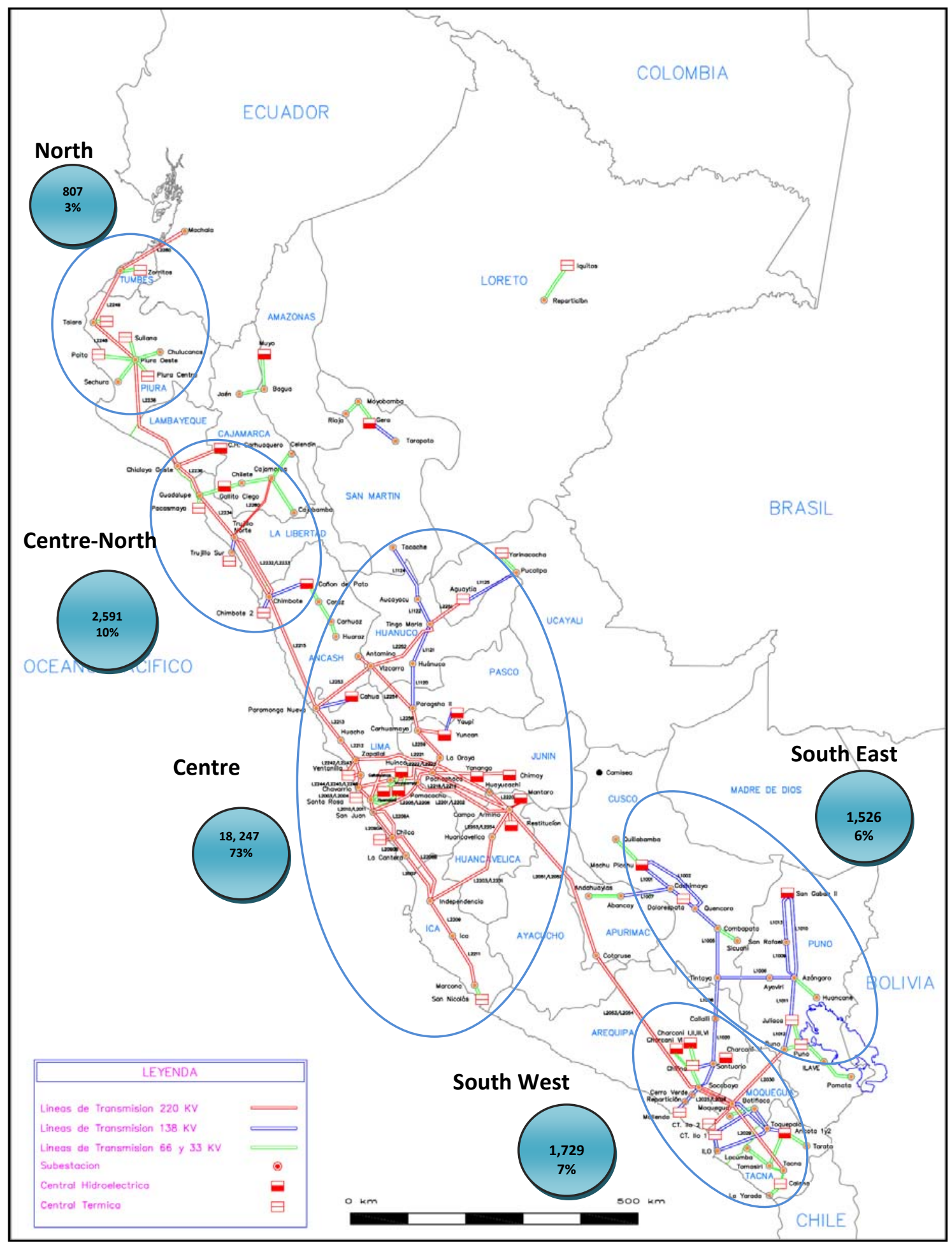

Sources: COES map and data from OSINERGMIN for year 2009 


\section{Results}

This section presents the information used and the main results in order to evaluate the HRV mechanism for the transmission expansion in the Peruvian electricity transmission system.

The information used for the simulations is very detailed in terms of the characteristics of thermal and hydropower plants, patterns of energy demand and transmission lines. This information was collected from the information systems of OSINERGMIN and COES. The website of OSINERGMIN provides information on the characteristics of power plants (maximum and minimum capacity, location), nodes (voltage level and location), transmission lines (voltage level, length, resistance, reactance and transmission capacity). The data on patterns of energy demand was supplemented by information from the COES.

In summary, the model includes 103 nodes, 203 lines (with voltage level between 33 and $220 \mathrm{kV}$ ), 45 thermal generation units and 44 hydropower generation units. Table 1 shows the installed capacity by technology in the Peruvian electricity system in 2009. Hydropower technology represents around 49\% of total installed capacity. Table 2 shows the impact of the Camisea natural gas in electricity generation capacity. In December 2009, the Camisea natural gas accounted for $31.38 \%$ of the total installed capacity. 
Table 1: Installed capacity by technology (MW)

\begin{tabular}{|c|c|c|}
\hline \multicolumn{1}{|c|}{ Generation } & Installed Capacity & \% \\
\hline Hydroelectric & $2,858.47$ & $48.88 \%$ \\
\hline Thermal & $2,988.87$ & $51.12 \%$ \\
\hline Gas & $1,896.14$ & $32.43 \%$ \\
Diesel & 226.27 & $3.87 \%$ \\
Steam & 357.02 & $6.11 \%$ \\
Combined cycle & 509.44 & $8.71 \%$ \\
\hline Total & $\mathbf{5 , 8 4 7 . 3 4}$ & $\mathbf{1 0 0 . 0 0 \%}$ \\
\hline
\end{tabular}

Source: OSINERGMIN

Table 2: Installed capacity by technology with Camisea natural gas (MW)

\begin{tabular}{|l|c|c|}
\hline \multicolumn{1}{|c|}{ Generation } & Installed Capacity & \% \\
\hline Hydroelectric & $2,858.47$ & $48.88 \%$ \\
\hline Camisea natural gas & $1,835.10$ & $31.38 \%$ \\
\hline Other thermals & $1,154.77$ & $19.75 \%$ \\
\hline \multicolumn{1}{|c|}{ Total } & $\mathbf{5 , 8 4 8 . 3 4}$ & $\mathbf{1 0 0 . 0 0 \%}$ \\
\hline
\end{tabular}

\section{Source: OSINERGMIN}

The model has two level of optimization. Then, solving the lower level problem that is a costs minimization problem, the vectors of optimal values of generation, as well as nodal prices, are obtained and substituted into the upper level problem with the information of energy demand. Then the optimal values of expansion capacity and fixed fee $F$ are in turn obtained. ${ }^{17}$

The lower level problem is simulated for 24 hours and in order to evaluate the transmission expansion the upper level problem take into account the average of nodal prices during each 24 hours. In this sense, the model considers each 24 hours from the lower level problem as a representative period to assess the transmission expansion.

\footnotetext{
${ }^{17}$ The part of the lower level problem is a simplified version of a more detailed power flow model developed by Jeff Pavlovic (2010). The model is simulated in GAMS and provides results for an hour.
} 
Assuming a linear cost for the transmission expansion $(\$ 750 / \mathrm{MW} / \mathrm{km})$ and Laspeyres weights, the expansion problem is evaluated for 10 representative periods.

Figure 3 shows the evolution of averaged nodal prices by zone over 10 periods. In the first period the prices differ as they are subject to the problem of congestion. The North and South zones have higher nodal prices, while the Centre zone has lower nodal prices. The average of the nodal prices in the first period is $\$ 40.77 / \mathrm{MWh}$. However, the nodal prices converge to a common value during the period of evaluation. In the final period, the average of the nodal price is $\$ 37.3$ (10\% lower compared to the average nodal price at the beginning of the simulation). This reduction of prices in the North and South zones reflects the situation mentioned before. Transmission congestion separates the Centre zone of the system from the remainder, and the prices on the North and South zones are higher compared with the Centre zone.

Figure 3: Price evolution by zone (Average)

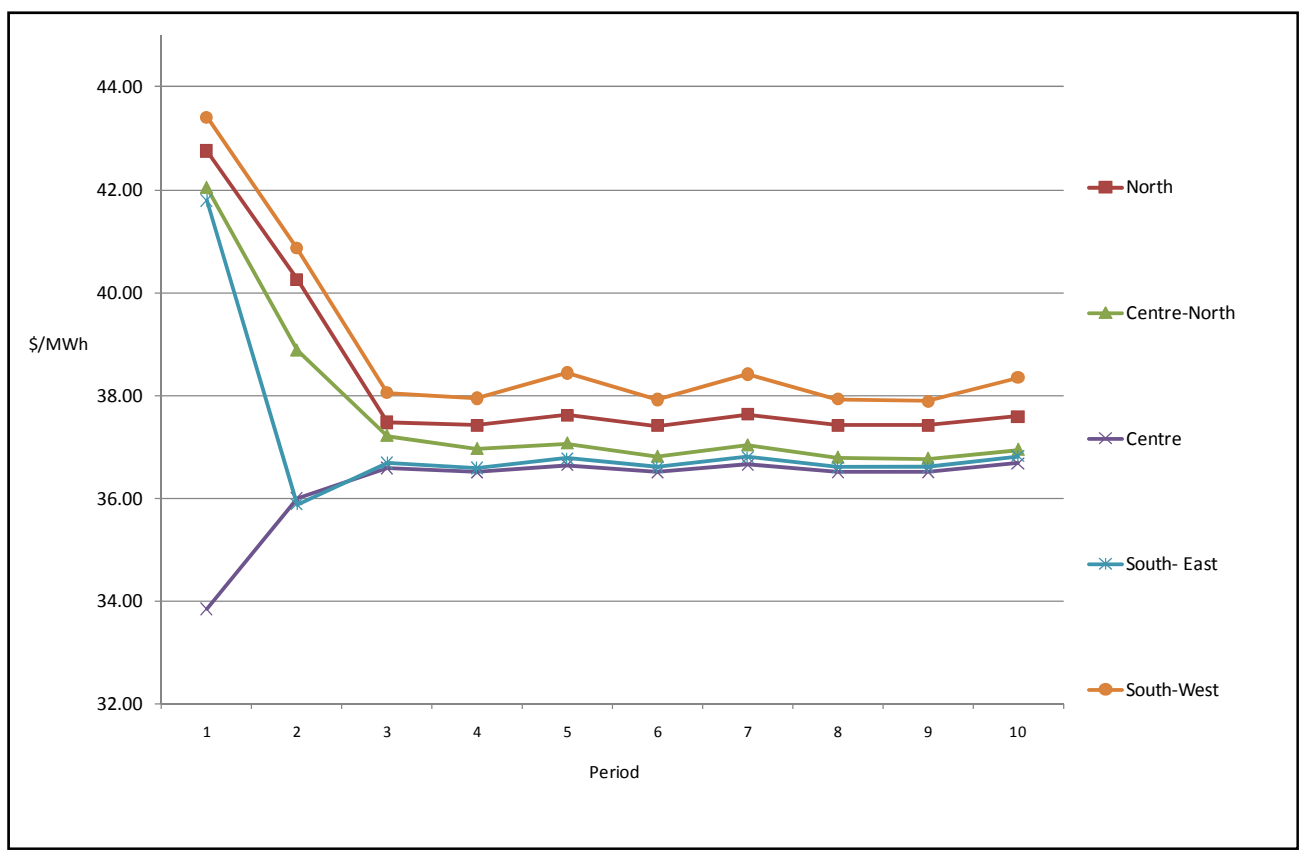

Source: Own elaboration 
Finally, Table 3 shows the evolution of transmission capacity of the main transmission lines in the Peruvian system (with $220 \mathrm{kV}$ of voltage level). It is important to note that lines as Huacho-Paramonga-Chimbote and Mantaro-Socabaya show important increments in their capacity. These transmission lines are very important in order to connect the Centre zone with the North and South zone respectively. In this sense, the mechanism for the expansion of electricity transmission allows transmission of lower-cost energy to the zones with more expensive energy generation and increasing demand.

Table 3: Transmission capacity evolution (MVA)

\begin{tabular}{|c|c|c|c|c|c|c|c|c|c|c|c|}
\hline Zone & $\begin{array}{r}\text { Line } \\
\end{array}$ & Period 1 & Period 2 & \begin{tabular}{|l|} 
Period 3 \\
\end{tabular} & Period 4 & Period 5 & Period 6 & Period 7 & Period 8 & Period 9 & Period 10 \\
\hline North & S.E. Malácas (Talara) - S.E. Piura Oeste & 325.4 & 425.9 & 518.0 & 583.9 & 622.1 & 632.4 & 632.4 & 632.4 & 632.4 & 632.4 \\
\hline North & S.E. Chiclayo Oeste - S.E. Guadalupe & 196.0 & 196.0 & 196.0 & 196.0 & 196.0 & 196.0 & 196.0 & 196.0 & 196.0 & 196.0 \\
\hline North & S.E. Guadalupe 1 - S.E. Trujillo Norte & 235.2 & 235.2 & 235.2 & 235.2 & 235.2 & 235.2 & 235.2 & 235.2 & 235.2 & 235.2 \\
\hline North & S.E. Chimbote 1 - S.E. Paramonga Nueva & 235.2 & 418.3 & 470.9 & 470.9 & 470.9 & 470.9 & 470.9 & 470.9 & 470.9 & 470.9 \\
\hline North & S.E. Paramonga Nueva - S.E. Vizcarra & 186.7 & 225.3 & 587.8 & 587.8 & 587.8 & 587.8 & 587.8 & 587.8 & 587.8 & 587.8 \\
\hline North & S.E. Paramonga Nueva - S.E. Huacho & 235.0 & 354.7 & 370.2 & 378.4 & 378.4 & 378.4 & 378.4 & 378.4 & 378.4 & 378.4 \\
\hline North & S.E. Huacho - S.E. Zapallal & 235.0 & 303.6 & 303.6 & 303.6 & 303.6 & 303.6 & 303.6 & 303.6 & 303.6 & 303.6 \\
\hline North & S.E. Chavarría - S.E. Santa Rosa & 470.0 & 734.7 & 734.7 & 734.7 & 734.7 & 734.7 & 734.7 & 734.7 & 734.7 & 734.7 \\
\hline North & S.E. Paragsha II - S.E. Huánuco & 44.1 & 44.1 & 44.1 & 44.1 & 44.1 & 44.1 & 44.1 & 44.1 & 44.1 & 44.1 \\
\hline North & S.E. Huánuco - S.E. Tingo María & 44.1 & 44.1 & 44.1 & 44.1 & 44.1 & 44.1 & 44.1 & 44.1 & 44.1 & 44.1 \\
\hline North & S.E. Pachachaca - La Oroya Nueva & 313.6 & 313.6 & 313.6 & 313.6 & 313.6 & 313.6 & 313.6 & 313.6 & 313.6 & 313.6 \\
\hline North & S.E. Oroya - Carhuamayo & 181.5 & 181.5 & 181.5 & 181.5 & 181.5 & 181.5 & 181.5 & 181.5 & 181.5 & 181.5 \\
\hline North & S.E. Carhuamayo - Paragsha & 245.0 & 245.0 & 245.0 & 245.0 & 245.0 & 245.0 & 245.0 & 245.0 & 245.0 & 245.0 \\
\hline North & S.E. Paragsha - Vizcarra & 181.5 & 181.5 & 181.5 & 181.5 & 181.5 & 181.5 & 181.5 & 181.5 & 181.5 & 181.5 \\
\hline Interconnection & S.E. Mantaro - S.E. Cotaruse & 900.0 & 1479.4 & $1,709.2$ & $1,802.0$ & $1,802.0$ & $1,802.0$ & $1,802.0$ & $1,802.0$ & $1,802.0$ & $1,802.0$ \\
\hline Interconnection & S.E. Cotaruse - S.E. Socabaya & 900.0 & 1303.9 & $1,417.9$ & $1,449.1$ & $1,449.1$ & $1,449.1$ & $1,449.1$ & $1,449.1$ & $1,449.1$ & $1,449.1$ \\
\hline South & S.E. Cerro Verde - S.E. Repartición & 88.2 & 88.2 & 88.2 & 88.2 & 88.2 & 88.2 & 88.2 & 88.2 & 88.2 & 88.2 \\
\hline South & S.E. Repartición - S.E. Mollendo & 88.2 & 88.2 & 88.2 & 88.2 & 88.2 & 88.2 & 88.2 & 88.2 & 88.2 & 88.2 \\
\hline South & S.E. Quencoro - S.E. Dolorespata & 70.6 & 70.6 & 70.6 & 70.6 & 70.6 & 70.6 & 70.6 & 70.6 & 70.6 & 70.6 \\
\hline South & S.E. Tintaya - S.E. Ayaviri & 88.2 & 88.2 & 88.2 & 88.2 & 88.2 & 88.2 & 88.2 & 88.2 & 88.2 & 88.2 \\
\hline South & S.E. Ayaviri - S.E. Azángaro & 176.4 & 176.4 & 176.4 & 176.4 & 176.4 & 176.4 & 176.4 & 176.4 & 176.4 & 176.4 \\
\hline South & S.E. Socabaya - S.E. Moquegua & 293.5 & 293.5 & 293.5 & 293.5 & 293.5 & 293.5 & 293.5 & 293.5 & 293.5 & 293.5 \\
\hline South & S.E. Moquegua - S.E. Tacna & 146.8 & 223.9 & 301.0 & 378.1 & 455.2 & 532.3 & 609.4 & 686.5 & 763.6 & 840.7 \\
\hline South & S.E. Moquegua- S.E. Puno & 146.8 & 351.6 & 543.7 & 687.3 & 758.2 & 758.2 & 758.2 & 758.2 & 758.2 & 758.2 \\
\hline
\end{tabular}

Source: Own elaboration

\section{Conclusions}

This research presents an application of the HRV mechanism for electricity transmission expansion in the Peruvian electricity transmission system. The model is based on a Transco that maximize profits subject to a regulatory constraint, and a competitive wholesale market with nodal price setting and Financial Transmission Rights (FTR). The regulation to the Transco is applied through a price cap on a two-part tariff. This regulation allows for the rebalancing of the variable and fixed charges in order to let the Transco preserve profits 
when congestion rents decrease due to the increased transmission network capacity. The Laspeyres weights are used in the two-part tariff regulation. The wholesale is operated by an ISO that coordinates generation and transmission, minimizing the total cost. FTR's are the signal for the need for expansion in transmission capacity.

The HRV mechanism used in this research allows the arbitrage of nodal prices and to foster their convergence to an equilibrium with lower congestion and higher total welfare (in terms of minimizing the operation of the system). The increases in the transmission capacity allow transmission of lower-cost energy to the zones with increasing demand and expensive energy generation. The mechanism is applied to the Peruvian electricity transmission system that is a region that suffers higher level of congestion with increasing demand. The problem is due to the absence of investment by private actors, which has required that principal investments in transmission have been executed by decision of the State through mechanisms as contracts BOOT. In order to overcome these problems a second reform was carried out. This second reform introduce important changes, among which the development of transmission by a centrally planned to be developed by the COES. However, is still in discussion the introduction of FTR's in the transmission system.

In this context, the HRV mechanism is applied to the Peruvian electricity transmission system taking into account 103 nodes and 203 lines. Starting with a network that suffers congestion in the North and South zones of the country, the simulation of the mechanism proves that after few periods the congestion is reduced and nodal prices converge to a common lower average. The simulation proves that the mechanism works for a more complicated topology with many nodes and lines, and with a detailed modeling of the lower level problem. In this sense, given the elements of the mechanism and its 
characteristics, this research contributes to the actual discussion about the introduction of FTR's in the Peruvian electricity transmission system.

\section{Bibliography}

Comité de Operación Económica del Sistema Interconectado Nacional- COES-SINAC webpage http://www.coes.org.pe

Hogan, W. (2002) “Financial Transmission Tight Formulations”, mimeo, JFK School of Government, Harvard Electricity Policy Group, Harvard University. USA (http://www.hks.harvard.edu/fs/whogan/).

Hogan, W., Rosellón, J., and I. Vogelsang (2010) “Toward a Combined MerchantRegulatory Mechanism for Electricity Transmission Expansion”, Journal of Regulatory Economics 38 (2), 113-143. .

Joskow, P. and J. Tirole (2002) “Transmission Investment: Alternative Institutional Frameworks”, Journal of Industrial Economics 53, 233-264.

Kristiansen, T. and J. Rosellón (2006) “A Merchant Mechanism for Electricity Transmission Expansion”, Journal of Regulatory Economics 29, 167-193.

Ministerio de Energía y Minas webpage http://www.minem.gob.pe/electricidad/index.asp Rosellón, J. Myslíkova, Z., and E. Zenón (2010) “Incentives for Transmission Investment in the PJM Electricity Market: FTRs or Regulation (or both?)”, Utilities Policy (forthcoming)

Organismo Supervisor de la Inversión en Energía y Minería - OSINERGMIN, webpage http://www.osinergmin.gob.pe

Pavlovic, Jeff. (2010) “Un Modelo para "Unit Commitment and Economic Dispatch" del Sistema Eléctrico Nacional (SEN) Mexicano para Manejar de Manera Óptima una Alta 
Penetración de Generación Eólica.” Centro de Investigación y Docencia Económicas para obtención del grado de Maestro en Economía (Master’s Thesis).

Rosellón, J. (2009) Mechanisms for the Optimal Expansion of Electricity Transmission networks. In Joanne Evans and Lester C Hunt (eds.), International Handbook on the Economics of Energy. Edward Elgar Publishing. UK.

Rosellón, J. and H. Weigt (2011) “A Dynamic Incentive Mechanism for Transmission Expansion in Electricity Networks- Theory, Modeling and Application”, The Energy Journal, vol.32, no. 1.

Sioshansi, F. and W. Pfaffenberger (eds.) (2006) Electricity-Market Reform: An International Perspective, Elsevier. Great Britain.

Vogelsang, I. (2001) “Price Regulation for Independent Transmission Companies”, Journal Regulatory Economics 20: 141-165.

Vogelsang, I. (2006) “Electricity Transmission Pricing and Performance-Based Regulation”, The Energy Journal 27(4): 97-126.

Wilson, R. (2002) “Architecture of Power Markets”, Econometrica 70(4): 1299-1340. 